\title{
Job satisfaction and attitudes towards nursing care among nurses working at Mzuzu Central Hospital in Mzuzu, Malawi
}

\author{
Maloni Nyirenda, Patricia Mukwato \\ Department of Nursing Sciences, School of Medicine, University of Zambia
}

Correspondence: Mr Maloni Nyirenda (zebediakaunga@gmail.com)

\section{Background}

\section{Abstract}

Job satisfaction is a major determinant of performance at the workplace. Studies have shown that job dissatisfaction can intensify emotional exhaustion, and this can influence nurses to perceive their work as tiresome and repetitive, leading to frustration and discouragement. The purpose of this study was to investigate the relationship between job satisfaction and attitude towards nursing care at Mzuzu Central Hospital in Mzuzu, Malawi.

Methods

This was a descriptive correlational study. Eighty-nine nurses were selected using simple random sampling. A self-administered questionnaire was used to collect data. Data were analysed using Stata (version 12). Frequencies, means, and standard deviations were used to summarise sociodemographic data and also to determine job satisfaction and attitudes towards nursing care among the participants. Independent t-tests were used to determine if differences in professional qualifications, job title, work experience, or the clinical setting in which the nurses worked were associated with differences in job satisfaction and attitude. Pearson's product-moment correlation was used to determine the relationship between job satisfaction and attitude in the study sample.

Results

The nurses who participated in this study generally had positive attitudes towards nursing care and were moderately satisfied with their jobs. There was a significant variation in attitude depending on the amount of time a nurse worked at a particular post $(\mathrm{P}=0.0308)$, as well as the amount of time a nurse had worked at the hospital $(\mathrm{P}=0.0012)$. There was a significant positive relationship between job satisfaction and attitude $(\mathrm{r}=0.226, \mathrm{P}=0.033)$.

Conclusions

The nurses in the study sample were moderately satisified with their work and generally had positive attitudes towards nursing care. There was a positive correlation between attitude towards nursing care and job satisfaction. Addressing factors which dissatisfy nurses can promote nurses' attitudes and likely improve performance and patient care.

\section{Introduction}

Nurses work at the frontlines of most healthcare systems, and their contributions are recognised as essential in delivering effective patient care. ${ }^{1}$ Providing quality nursing care is therefore an important consideration when discussing patient care standards. Nurses who are satisfied with their work and with the conditions under which care is provided are more likely to provide quality care that satisfies the patient. Literature has shown that job dissatisfaction leads nurses to have negative attitudes towards their work, which negatively affects the quality of care they provide. ${ }^{2}$

Nurses' job satisfaction is defined as the degree to which nurses like or enjoy the work they do. ${ }^{3}$ Job satisfaction is important in healthcare organisations because it is an indicator of the physical and psychological states of employees. ${ }^{4}$ The attitude that a nurse holds towards patients and their state of ill health strongly determines the quality and extent of the emotional, physical, and psychological help that patients receive from that nurse. ${ }^{5}$ Attitude is an evaluative disposition; a tendency to like or dislike, or to act favourably or unfavourably towards someone or something, which might have an impact on the way someone behaves towards that person or object. ${ }^{6,7}$

It is established that optimal and compassionate nursing care is negatively affected by critical shortages of staff, heavy workload, low salaries, lack of support and respect from managers, inter-staff conflict, and poor quality of equipment and materials, among other factors. ${ }^{8-12}$ Such challenges may predispose nurses to negative attitudes and unprofessional conduct. The public opinion of nurses and their ability http://dx.doi.org/10.4314/mmj.v28i4.3 to provide safe, quality, and compassionate care has been affected by such unprofessional conduct, incidences of which have subsequently become the subjects of media headlines. ${ }^{13}$ Newspapers from Malawi and elsewhere in subSaharan Africa have reported about nurses' negative attitudes, negligence, and malpractice. ${ }^{14-18}$ Furthermore, a content analysis of South African newspapers found that there were few articles that portrayed the image of nursing as a caring, compassionate, and knowledgeable profession, while many articles indicated that nurses were overworked, uncaring, lazy, and suffering from burnout, with a general portrayal of negative attitude. ${ }^{19}$ Studies conducted in Malawi have reported that negative attitudes among nurses are sometimes manifested by rudeness and scolding of patients. ${ }^{8,20,21}$ Such behaviours are associated with job dissatisfaction among nurses. ${ }^{22-24}$

Patient and public complaints about the quality of nursing care in Malawi may be related to negative attitudes among nurses who are dissatisfied with their jobs. This study was conducted to investigate the relationship between nurses' job satisfaction and attitudes towards nursing care at Mzuzu Central Hospital in Malawi.

\section{Methods}

\section{Study design and setting}

This was a descriptive correlational study, designed to explore the relationship between job satisfaction and attitude among nurses at Mzuzu Central Hospital. The hospital is located in the city of Mzuzu and is a referral centre that has served all six districts in Malawi's Northern Region since opening in the year 2000 . 


\section{Population}

The study population included all nurses working at Mzuzu Central Hospital. Nurses were eligible to participate if they were registered by the Nurses and Midwives Council of Malawi (NMCM), had been employed for a year or more, were permanently employed, and were available during data collection period.

\section{Sample selection}

The study used simple random sampling, which was done by assigning a number to each eligible member of the population then using a random number table to select the sample.

\section{Sample size}

The correlation coefficient in the study was estimated at 0.34 after reviewing similar previous studies conducted in sub-Saharan Africa. Using Stata (version 12), an estimated sample size was calculated for a one-sample correlation test (Fisher's z-test). In order to observe a correlation of 0.34 , at an alpha of $5 \%$ with $80 \%$ power, a minimum sample size of 70 nurses was required.

\section{Ethical considerations}

Ethical approval to conduct this study was obtained from ERES Converge Institutional Review Board, a private ethical review board in Zambia, and the National Health Sciences Research Committee (NHSRC), Malawi. Permission to use Mzuzu Central Hospital as a study site was obtained from the hospital director. Written and verbal consent were obtained from all participants.

\section{Instruments}

A self-administered questionnaire was used to collect data from participants. The study used existing validated instruments, which had been used in similar previous studies. The study instruments used have high Cronbach's alphas, indicating their reliability to measure the variables in this study. The following instruments were used to collect data:

(i) Attitude was measured using the Attitude Scale for Nursing Profession (ASNP). It was developed by Coban and Kasikci to measure attitudes of nurses and students towards the nursing profession. It has 40 items subdivided into three domains. Cronbach's alphas for each of the three subscales range from 0.98 to 0.99 , while alpha is 0.91 for the whole scale. Each item is rated on a five-point Likert scale. ${ }^{25}$

(ii) Job satisfaction was measured using the McCloskey/Mueller Satisfaction Scale (MMSS). The scale was designed by McCloskey and Mueller to assess the satisfaction of hospital staff nurses. The scale has 31 items, which are further subdivided into eight subscales. Cronbach's alphas for each of the eight subscales range from 0.52 to 0.84 , while alpha is 0.89 for the scale as a whole. Each item is rated on a five-point Likert scale. ${ }^{26}$

\section{Data analysis}

Data were analysed using Stata (version 12). Frequencies, means, and standard deviations were used to summarise sociodemographic characteristics of the participants, as well as to determine overall job satisfaction and attitude. Independent t-tests were used to determine differences in job satisfaction and attitude based on different work-related variables (see Table 1 for variables captured). Pearson's product-moment correlation was used to determine the relationship between job satisfaction and attitude within the study sample. Both instruments were scored and interpreted in the same way: each item was scored from 1 to 5 , with 5 indicating the most positive attitude and highest level of satisfaction on the respective questionnaires. Negatively worded items from the ASNP were reversecoded before calculating mean scores. A mean score above 3.0 was interpreted as a positive attitude towards nursing or satisfaction with nursing work. The overall means for both scales gave us the general measures of nurses' job satisfaction and attitudes towards nursing care in our study sample.

\section{Results}

One hundred questionnaires were administered to participants meeting the eligibility criteria and 89 questionnaires were returned, representing an $89 \%$ response rate. Data collection was carried out in April 2014.

\section{Sociodemographic data}

The ages of participants ranged from 24 to 71 years (mean $=38.2 \pm 12.6$ years). The majority of respondents were females $(n=76)$ and married $(n=59)$. Forty-one respondents had diplomas in nursing and two had master of science in nursing degrees. Sixty were nurse midwife technicians. Fiftytwo of the participants had been at their current posts for more than 4 years. The respondents' duration of working as nurses ranged from 1 year to 42 years $($ mean $=12.9 \pm 11.7$ years) while duration working at Mzuzu Central Hospital ranged from 0.1 to 14 years (mean $=6.4 \pm 4.9$ years). The participants were drawn from all wards and departments of the hospital, with the highest representation coming from the outpatient department ( $n=25)$, while there were only three participants from the intensive care unit (Table 1).

\section{Nurses' attitudes towards nursing care}

The mean scores on each of the 40 items of the ASNP ranged from 1.66 to 4.72 (Table 2). The mean ASNP scores for individual respondents ranged from 3.2 to 4.7 . The overall mean ASNP score (4.04 \pm 0.34$)$ suggests a generally positive attitude among the nurses towards nursing care. The study revealed a significant difference $(\mathrm{P}=0.031)$ in attitude between nurses who had been working at their current positions for less than 4 years (mean ASNP score $=3.94$ $\pm 0.34)$ and those who had worked at their current posts for longer (mean ASNP score $=4.10 \pm 0.33$ ). There was also a significant mean difference $(\mathrm{P}=0.001)$ with regards to attitude when comparing nurses who had worked at the hospital for less than seven years (mean ASNP score $=3.95$ \pm 0.34 ) with those who had worked at the hospital for longer (mean ASNP score $=4.18 \pm 0.28$ ). The other investigated variables yielded no statistically significant variations in the participants' attitudes towards nursing care.

\section{Nurses' job satisfaction}

The mean satisfaction scores on the 31 MMSS items ranged from 1.94 to 3.90, and respondents were dissatisfied with 11 out of 31 items (Table 3 ).

The respondents were most satisfied with their relationships with coworkers (mean MMSS score $=3.87 \pm 0.89$ ), praise and recognition (mean MMSS score $=3.34 \pm 0.87$ ), and balance of family and work (mean MMSS score $=3.34 \pm 0.97$ ). They were most dissatisfied with two of the eight subscales: professional opportunities (mean MMSS score $=2.39 \pm 0.92$ ) and extrinsic rewards (mean MMSS score $=2.50 \pm 0.99$ ). The individual participants' mean satisfaction scores ranged from 1.30 to 4.28. Thirty-three of the participants' mean scores indicated 
Table 1: Work-related characteristics of nurses in the study sample

\begin{tabular}{lc}
\hline Variable $(\mathbf{N}=\mathbf{8 9})$ & $\mathbf{n}$ \\
\hline Professional qualification & 25 \\
\hline Bachelor of Science in Nursing & 2 \\
Diploma (Registered Nurse) & 39 \\
Diploma (Nurse Midwife Technician) & 21 \\
Certificate & 2 \\
Master of Science in Nursing & 2
\end{tabular}

\section{Current post}

Nurse Midwife Technician

Senior Nurse Midwife Technician $\quad 0$

$\begin{array}{ll}\text { Nursing Officer } & 22\end{array}$

$\begin{array}{ll}\text { Senior Nursing Officer } & 0\end{array}$

$\begin{array}{ll}\text { Principal Nursing Officer } & 6\end{array}$

$\begin{array}{ll}\text { Chief Nursing Officer } & 1\end{array}$

\begin{tabular}{lr}
\hline Duration at the current post (in years) \\
\hline $1-4$ & 37 \\
$5-8$ & 22 \\
$9-12$ & 19 \\
$>12$ & 11
\end{tabular}

\section{Clinical setting}

Female Medical Ward 5

Intensive Care Unit 3

Female Surgical Ward 4

OPD (Emergency Department, Minor Theatre, X-Ray, $\quad 21$

Antenatal Clinic, ART Clinic, Ambulatory)

Male Surgical Ward 5

Gynaecological Ward $\quad 6$

Postnatal Ward 5

Tuberculosis Ward 5

Male Medical Ward 4

$\begin{array}{lr}\text { Main Operating Theatre } & 8\end{array}$

Maternity Ward 11

$\begin{array}{ll}\text { Paediatric Ward } & 8\end{array}$

Eye Ward 4

OPD = Outpatient Department; ART = antiretroviral therapy 
Table 2: Nurses' attitudes towards nursing care (Attitude Scale for Nursing Profession) ${ }^{25}$

Attitude item/subscale $(\mathrm{N}=89)$

Mean score

$\pm \mathrm{SD}$

Properties of the nursing profession subscale

$4.33 \pm 0.36$

Nursing is a profession that requires continuous reading and keeping up with the technology.

$4.66 \pm 0.60$

Nursing will exist as long as humanity exists.

$4.65 \pm 0.62$

Nursing is a profession that requires skills besides knowledge.

$4.65 \pm 0.76$

What I love most about nursing is the opportunity it provides to help people.

$4.47 \pm 0.71$

I think nursing is one of the leading professions that embrace a significant dimension of conscience.

$4.17 \pm 0.92$

Nursing can be practiced only by enthusiasm.

$3.66 \pm 1.31$

Nursing cannot afford any mistakes.

$2.28 \pm 1.38$

Preference to the nursing profession subscale $4.01 \pm 0.06$

I think nurses are indispensable members of the health staff.

$4.72 \pm 0.63$

Nursing requires a lot of patience.

$4.69 \pm 0.47$

I think nursing requires calmness and equanimity

$4.69 \pm 0.47$

I think communication is crucial in nursing.

$4.63 \pm 0.61$

Nursing requires more empathy than other professions.

$4.60 \pm 0.62$

I think nursing profession is an indispensable profession for a society.

$4.52 \pm 0.59$

Nurses should be compassionate.

$4.51 \pm 0.68$

Nurses should be good people.

$4.46 \pm 0.74$

I hate this profession.

$4.46 \pm 0.87$

I prefer being unemployed rather than practicing nursing.

$4.46 \pm 0.89$

I can never practice nursing.

$4.42 \pm 0.96$

Nursing is a holy and noble profession because it gives service directly to people.

$4.35 \pm 0.77$

I think it is important that nurses have personal characteristics like good humour,

$4.35 \pm 0.80$

insightfulness, devotion and charity.

$4.30 \pm 0.79$

Nursing is not preferred as a profession unless one has no other choices left.

$4.19 \pm 1.14$

I have always admired the profession of nursing.

$4.16 \pm 1.05$

I think nursing is the most appropriate profession for me.

$4.11 \pm 1.09$

I think nursing is not a cheerful profession.

$4.02 \pm 1.13$

I think the spiritual satisfaction of nursing is more important than its material satisfaction.

$3.96 \pm 1.03$

I think nursing is a promising profession.

$3.79 \pm 1.15$

I would practice nursing in any condition.

$3.71 \pm 1.26$

Nursing is an honourable profession.

$3.64 \pm 1.23$

I would not like my children to become nurses.

$3.54 \pm 1.31$

Nursing is very close to my ideal profession in mind.

$3.27 \pm 1.39$

General position of the nursing profession subscale

I think nurses among all health-care personnel communicate the most with patients.

Nursing is a profession requiring taking great responsibilities.

Nursing is a profession requiring sacrifice.

I think nursing profession has not reached the state it deserves.

Job opportunities are more abundant in the profession of nursing.

I think the health of a society depends on nurses.

I think that not everybody can become a nurse.

Nursing is a very exhausting profession. 
Table 3: Nurses' job satisfaction (McCloskey/Mueller Satisfaction Scale) ${ }^{26}$

\begin{tabular}{|c|c|}
\hline Job satisfaction item/subscale $(\mathrm{N}=\mathbf{8 9})$ & $\begin{array}{c}\text { Mean score } \\
\pm S D\end{array}$ \\
\hline Satisfaction with professional opportunities subscale & $2.39 \pm 0.92$ \\
\hline Opportunities to belong to department and institutional committees & $3.06 \pm 1.26$ \\
\hline Opportunities to interact with faculty of the College of Nursing & $2.52 \pm 1.24$ \\
\hline Opportunities to participate in nursing research & $2.03 \pm 1.28$ \\
\hline Opportunities to write and publish & $1.94 \pm 1.23$ \\
\hline Satisfaction with extrinsic rewards subscale & $2.50 \pm 0.99$ \\
\hline Vacation & $2.96 \pm 1.38$ \\
\hline Salary & $2.34 \pm 1.37$ \\
\hline Benefits package (insurance, retirement) & $2.20 \pm 1.19$ \\
\hline Satisfaction with control and responsibility subscale & $3.05 \pm 0.09$ \\
\hline Your amount of responsibility & $3.45 \pm 1.17$ \\
\hline Control over what goes on in your work setting & $3.22 \pm 1.17$ \\
\hline Your control over work conditions & $3.13 \pm 1.20$ \\
\hline Your participation in organizational decision making & $2.78 \pm 1.35$ \\
\hline Opportunities for career advancement & $2.69 \pm 1.33$ \\
\hline Satisfaction with scheduling subscale & $3.15 \pm 1.01$ \\
\hline Opportunity to work straight days & $3.62 \pm 1.16$ \\
\hline Weekends off per month & $3.40 \pm 1.39$ \\
\hline Flexibility in scheduling your weekends off & $3.35 \pm 1.39$ \\
\hline Flexibility in scheduling your hours & $3.28 \pm 1.23$ \\
\hline Hours that you work & $3.03 \pm 1.27$ \\
\hline Compensation for working weekends & $2.22 \pm 1.45$ \\
\hline Satisfaction with interaction opportunities subscale & $3.31 \pm 0.92$ \\
\hline The delivery of care method used on your unit (e.g. functional, team, primary) & $3.66 \pm 0.90$ \\
\hline Opportunities to interact professionally with other disciplines & $3.25 \pm 1.24$ \\
\hline Opportunities for social contact with your colleagues after work & $3.18 \pm 1.27$ \\
\hline Opportunities for social contact at work & $3.16 \pm 1.23$ \\
\hline Satisfaction with the balance of family and work subscale & $3.34 \pm 0.97$ \\
\hline Maternity leave time & $3.90 \pm 1.13$ \\
\hline Opportunity for part-time work & $3.08 \pm 1.41$ \\
\hline Child care facilities & $3.03 \pm 1.32$ \\
\hline Satisfaction with praise and recognition subscale & $3.34 \pm 0.87$ \\
\hline Your immediate supervisor & $3.89 \pm 1.02$ \\
\hline Recognition of your work from peers & $3.70 \pm 1.04$ \\
\hline Recognition for your work from superiors & $2.89 \pm 1.33$ \\
\hline Amount of encouragement and positive feedback & $2.89 \pm 1.34$ \\
\hline Satisfaction with coworkers subscale & $3.87 \pm 0.81$ \\
\hline The physicians you work with & $3.88 \pm 0.90$ \\
\hline Your nursing peers & $3.87 \pm 0.93$ \\
\hline Overall satisfaction mean score & $3.12 \pm 0.65$ \\
\hline
\end{tabular}

$\mathrm{SD}=$ standard deviation

Scores range from 1 (strongly disagree) to 5 (strongly agree) 
dissatisfaction with their jobs. The overall mean MMSS score (3.12 \pm 0.65$)$, suggests moderate job satisfaction among the study participants. There were no statistically significant differences in job satisfaction levels when comparing participants from different categories of the investigated work-related variables.

\section{Association between nurses' job satisfaction and attitude}

Pearson's product-moment correlation coefficient ( $\mathrm{r}$ ), as calculated using the data collected in this study, revealed a significant positive correlation between job satisfaction and attitude towards nursing care $(\mathrm{r}=0.226, \mathrm{P}=0.033)$. There were also significant positive correlations between job satisfaction and attitude subscales (Table 4). Attitudes towards properties of the nursing profession positively correlated with satisfaction with balance of family and work $(\mathrm{r}=0.2428, \mathrm{P}=$ 0.0219). Preference to the nursing profession positively correlated with satisfaction with coworkers $(\mathrm{r}=0.2605, \mathrm{P}=0.0137)$ and satisfaction with praise and recognition $(\mathrm{r}=0.2911, \mathrm{P}=0.0057)$.

\section{Discussion}

This study revealed a significant association between nurses' job satisfaction and attitudes towards nursing care, both in general and related to specific domains of enquiry into job satisfaction and attitudes that were assessed in this study.

\section{Nurses' attitudes}

The present findings on the nurses' attitudes towards nursing care using the ASNP suggest a positive attitude among the nurses included in this study. A review of literature from Malawi and sub-Saharan Africa yielded few studies that aimed at determining the relationship between nurses' job satisfaction and their attitudes.

A study of nursing students' attitudes towards the nursing profession, using the ASNP in Saudi Arabia, reported that $67.1 \%$ had a positive attitude. ${ }^{27}$ Similarly, a study to survey attitudes of acute mental health nurses in the United Kingdom reported that more than $80 \%$ of respondents displayed positive attitudes towards their work. ${ }^{28}$

Some qualitative studies done in Malawi reveal negative attitudes among some nurses. $8,20,21$ The differences in findings between these studies and the present study may be attributable to differences in the methodological approaches used in data collection.

The positive attitudes of the nurses towards nursing care may have several possible explanations. Perceived core values that are attached to the profession of nursing act as resources that help nurses achieve moral competence and adherence to their intrinsic work-related values, and this may enable nurses to enjoy their work and be more satisfied, ${ }^{8,29-31}$ despite challenges, such as limited resources, high workload, and low salaries.

The study revealed a significant difference in attitude between nurses who had held their current positions for less than 4 years and those who had held their posts for longer periods. These findings are supported by a study on nurses' professionalism in Ethiopia, which reported a significant relationship between professionalism and more years of experience. ${ }^{32}$ Nurses who have held their jobs for less than four years are likely to still be adjusting to their working environments, which could have a negative effect on their attitudes compared to senior nurses who are more acclimated to their working environments. Nurse leaders may therefore need to be aware of the need to nurture new nurses into the profession to promote positive attitudes.

http://dx.doi.org/10.4314/mmj.v28i4.3

\section{Nurses' job satisfaction}

The findings on job satisfaction using the MMSS revealed that respondents were moderately satisfied with their jobs. They were dissatisfied with 11 out of the 31 items and with two of the eight subscales. The respondents were most dissatisfied with professional opportunities and extrinsic rewards, while they were most satisfied with coworkers and praise and recognition. A study in South Africa using the MMSS reported moderate overall job satisfaction among nurses, with control and responsibility being the subscale that the participants were most dissatisfied with. ${ }^{33}$ In the present study, participants were neither satisfied nor dissatisfied with this aspect of their work. A study using the MMSS on nurses' job satisfaction in Hong Kong also reported a moderate satisfaction (mean score $=3.24 \pm 0.50$ ). However, unlike in the present study, the participants in the Hong Kong study were satisfied with 22 out of the 31 items and six of the eight subscales. They were most satisfied with extrinsic rewards, which was the lowest ranked subscale in the present study. However, as with our study, participants in the Hong Kong study were dissatisfied with professional opportunities. ${ }^{34}$ Extrinsic rewards and professional opportunities were the aspects of the job that were most commonly found to be dissatisfying by particpants in this study; other studies from Malawi and South Africa also found nurses to be dissatisfied with these particular subscales. ${ }^{22-24}$ The findings in several of the previous studies reviewed ${ }^{3,33,34,35}$ suggest moderate satisfaction among nurses, which is consistent with the findings of this study. These studies further suggest some satisfying and dissatisfying elements of the nursing profession across various cadres of nurses and cultures.

Participants of the present study were generally satisfied with the questionnaire content related to relationships with coworkers and praise and recognition. It is worth noting that nurses in this study were satisfied with praise and recognition from both peers and supervisors, which is contrary to some previous studies that have reported dissatisfaction with supervisors. ${ }^{36-38}$ Praise and recognition are important because supporting and motivating healthcare workers improves performance and quality care provision. ${ }^{23}$

The nurses in this study had been at their current posts between 0.3 and 20 years (mean $=6.58 \pm 4.40$ years) and 52 of the participants had been at their current posts for more than 4 years. The Malawi Public Service Regulations state that an employee shall be promoted to the next post after 4 years, depending on availability of vacancies at the next post. ${ }^{39}$ However, most of the participants had been at the same posts for more than 4 years, while there were few or no nurses occupying most of the senior positions (Table 1). This may cause job dissatisfaction and consequently negative attitudes affecting provision of quality nursing care.

\section{Association between nurses' job satisfaction and attitude}

There was a positive association between the nurses' job satisfaction and attitude $(r=0.226, \mathrm{P}=0.033)$. There were also positive correlatons between the subscales of job satisfaction and attitude (Table 4). These findings are similar to those of a study on nurses' job satisfaction and attitudes towards people living with HIV/AIDS in Russia, which found that job satisfaction was positively correlated with empathetic attitudes $(r=0.28, \mathrm{P}<0.001) .{ }^{40}$ Furthermore, a positive correlation between professionalism and job satisfaction $(\mathrm{r}=0.299, \mathrm{P}<0.001)$ was reported in a 
Table 4: Correlations between job satisfaction and attitude subscales

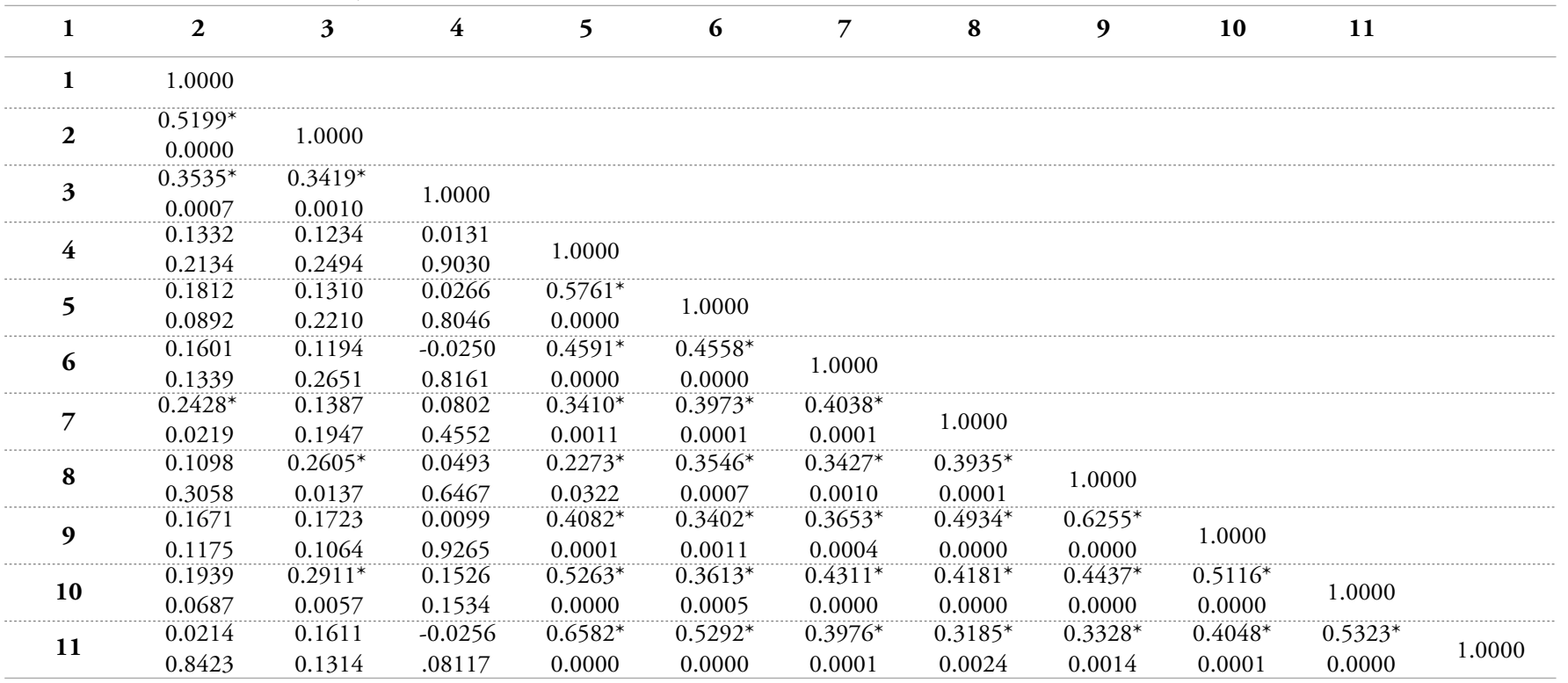

$1=$ Properties of the nursing profession; 2 = Preference to the nursing profession; 3 = General position of the nursing profession; $4=$ Satisfaction with professional opportunities; $5=$ Satisfaction with extrinsic rewards; 6 = Satisfaction with scheduling; 7 = Satisfaction with the balance of family and work; $8=$ Satisfaction with coworkers,

$9=$ Satisfaction with interaction opportunities; $10=$ Satisfaction with praise and recognition; $11=$ Satisfaction with control and responsibility

Values are Pearson's product-moment correlation coefficients

* = significant correlations

study, carried out in Turkey, to determine the effect of the professional behaviour of nurses on their job satisfaction. ${ }^{41}$ When nurses are satisfied with their jobs and the conditions under which care is provided, they are more likely to provide quality care that satisfies patients. Similarly, in a study to investigate job satisfaction and emotional well-being among Slovak nurses, a positive correlation between positive emotions and job satisfaction was observed $\left(r_{s}=0.262, \mathrm{P}\right.$ $=0.007) \cdot{ }^{42}$ High levels of stress and emotional exhaustion, resulting from job dissatisfaction, negatively affect nurses' attitudes, consequently negatively affecting patient care.

It is worth noting that the correlation coefficients in this study are positive but weak; this could be attributed to lower and variable mean scores related to job satisfaction. Furthermore, attitude and job satisfaction are multifaceted, complex, and highly subjective, and different studies show varying sources of job satisfaction. ${ }^{43,44}$ There are other factors that influence attitude apart from job satisfaction. These were beyond the scope of this study. Further studies are needed to explore other factors affecting nurses' attitudes in Malawi.

\section{Study limitations}

Self-reporting was used for data collection, and this could have introduced some level of bias that could have been mitigated by using mixed methods, for example, by adding focus group discussions to the study procedures. The study only established associations and did not investigate causal relationships.

\section{Conclusions}

The aim of the study was to investigate the relationship between job satisfaction and attitudes among nurses at Mzuzu Central Hospital. It revealed that these nurses were moderately satisfied with their work and had positive attitudes towards nursing care. The findings revealed a positive association between job satisfaction and attitude. The implications are that, with nurses playing such a prominent role in patient care, more emphasis needs to be put on researching and implementing strategies and interventions that can improve nurse job satisfaction, attitudes, and ultimately the quality of patient care.

http://dx.doi.org/10.4314/mmj.v28i4.3

\section{References}

1. Buchanan, J. and Aiken, L. Solving nursing shortages: a common priority. Journal of Clinical Nursing. 2008; 17(24): 3262-3268.

2. De Melo, M.B., Barbosa, M.A. and De Souza, P.R. Job satisfaction of nursing staff: integrative review. Revista Latino-Americana de Enfermagem. 2011; 19(4): 1047-1055.

3. Mrayyan M.T. Jordanian nurses' job satisfaction, patients' satisfaction and quality of nursing care. International Nursing Review. 2006; 53(3): 224-30.

4. Al- Dossary, R., Vail, J. and Mac Farlane, F. Job satisfaction of nurses in a Saudi Arabian University Teaching Hospital: a cross-sectional study. International Nursing Review. 2012; 59 (3): 424-430.

5. Rana, D. and Upton, D. Psychology for nurses. Edinburgh. Pearson Education,Inc.2008.Accessedathttp://www.amazon.co.uk/PsychologyNurses-Dr-Devinder-Rana/dp/0132001071\#reader_0132001071 on 20/102013

6. Greenwald, A.G. and Krieger, L.H. Implicit bias: scientific foundations. California Law Review. 2006; 94 (4): 945-968.

7. Mason, M. and Whitehead, T. Thinking nursing. Berkshire. Open University Press. 2003. Accessed at http://books.google.com.au/books/ about/Thinking_Nursing.html?id=6kvCppHoOpoC on 20/11/2013

8. Msiska, G., Smith, P. and Fawcett, T. Emotive responses to ethical challenges in caring: a Malawian perspective. Nursing Ethics. 2014; 21 (1): $97-107$.

9. Samir, N., Mohamed, R., Moustafa, E. and Saif, H.A. Nurses' attitudes and Reactions towards workplace violence in obstetrics and gynaecological departments in Cairo hospitals. Eastern Mediterranean Health Journal. 2012; 18(3): 198-204.

10. Van Der Doef, M., Mbazzi, F.B. and Verhoeven, C. Job conditions, job satisfaction, somatic complaints and burnout among East African nurses. Journal of Clinical Nursing. 2011; 21 (11-12): 1763-1775.

11. Yau S.Y, Xiao, X.Y, Lee, L.Y.K, Tsang, A.Y.K, Wong, S.L and Wong, K.F. Job stress among nurses in China. Journal of Applied Nursing Research. 2012; 25 (1): 60-64.

12. Manongi, R.N., Nasuwa, F.R., Mwangi, R., Reyburn, H., Poulsen, A. and Chandler, C.I.R. Conflicting priorities: evaluation of an intervention to improve nurse-parent relationship on a Tanzanian paediatric ward. Human Resources for Health. 2009; 7:50. 
13. Mc Sherry, R., Pearce, P., Grimwood, K, and Mc Sherry,W. The pivotal role of nurse managers, leaders and educators in enabling excellence in nursing care. Journal of Nursing Management. 2012; 20 (1): 7-19.

14. Sichone, C. Uncaring Kabwata clinic nurses angers patients. Times of Zambia. 29 June, 2013. Accesses at http://www.times. co.zm/?p=20934 on 4/10/2013.

15. Shaanika, H. Namibia: Nurses suspended over "negligence". All Africa. 8 April, 2013. Accessed at http://allafrica.com/ stories/201304081452.html on 4/10/2013.

16. Chinele, J. The safe motherhood question. The Nation. 4 April, 2012. Accessed at http://mwnation.com/the-safe-motherhood-question/ on $27 / 04 / 2013$

17. Mnkhwanazi, A. South Africa: patients fed up with bad attitude from nursing staff. The South Africa News Service, 27 June, 2012. Accessed at http://www.health-e.org.za/2012/06/27/patients-fed-upwith-bad-attitude-from-nursing-staff/ on 27/04/2013.

18. Potani, R. (2011). Some health workers scaring pregnant women. Believe Africa, 11 March, 2011. Accessed at http://believeafrica. tigblog.org/post/4458713 on 4/10/2013.

19. Oosthuizen, M.J. The portrayal of nursing in South African newspapers: a qualitative content analysis. Africa Journal of Nursing and Midwifery. 2012; 14(1): 49-62.

20. Kumbani, L., Chirwa, E., Malata, A., Odland, J.O. and Bjune, G. Why some women fail to give birth at health facilities: a qualitative study of women's perceptions of perinatal care from rural southern Malawi. Reproductive Health. 2013; 10:9.

21. Kumbani, L., Chirwa, E., Malata, A., Odland, J.O. and Bjune, G. Do Malawian women critically assess the quality of care? A qualitative study on women's perceptions of perinatal care at a district hospital in Malawi. Reproductive Health. 2012; 9:30.

22. Mokoka, E., Oosthuizen, M.J. and Ehlers, V.J. Retaining professional nurses in South Africa: nurse managers' perspectives. Health SA Gesondheid. 2010; 15(1): 1-9.

23. Bradley, S. and McAuliffe, E. Mid-level providers in emergency obstetric and newborn healthcare: factors affecting their performance and retention within the Malawian health system. Human Resources for Health. 2009; 7:14.

24. Selebi, C. and Minnaar, A. Job satisfaction among nurses in a public hospital in Gauteng. Journal of the Democratic Nursing Organisation of South Africa. 2007; 30(3): 53-61.

25. Coban, G.I. and Kasikci, M. Development of the attitude scale for nursing profession. International Journal for Nursing Practice. 2011; 17(5): 518-524

26. Mueller, C. W. and McCloskey, J. C. Nurses' job satisfaction: a proposed measure. Nursing Research. 1990; 39 (2), 113-117.

27. Miligi, E., and Selim, A. Saudi nursing students' attitude towards the nursing profession. 2013. Accessed at http://www.westeastinstitute. com/wp-content/uploads/2013/02/ANT13-290-Eman-Miligi-andAbeer-Selim-Abstract.pdf. on 24/05/2014

28. Munro, S. and Baker, J.A. Surveying attitudes of acute mental health nurses. Journal of Psychiatric and Mental Health Nursing. 2007; 14 (2): 196-202.
29. Ravari, A., Bazargan-Hejazi, S., Ebadi, A., Mirzaei, T. and Oshavandi, K. Work values and job satisfaction: a qualitative study of Iranian nurses. Nursing Ethics. 2013; 20(4): 448-458.

30. Usher, K., West, C., MacManus, M., Waqa, S., Stewart, L., Henry, R., et al. Motivations to nurse: an exploration of what motivates students in the Pacific Islandcountries to enter nursing. International Journal of Nursing Practice. 2013; 19 (5): 447-454.

31. Harrowing, J.N. Compassion practice by Ugandan nurses who provide HIV care. The Online Journal of Issues in Nursing. 2011; 16 (1): 1-14.

32. Fantahun, A., Demessie, A., Gebrekirstos, K., Zemene, K. and Yetayeh, G. A cross-sectional study on factors influencing professionalism in nursing among nurses in Mekelle public hospitals, north Ethiopia. BMC Nursing. 2014; 13:10.

33. Willis, W.G. The impact that career anchors and job compatibility of professional nurses has on job satisfaction: a predictor of turnover. 2011. Accessed at http://upetd.up.ac.za/thesis/available/etd-08112012194922/unrestricted/dissertation.pdf b on 10/06/2014

34. Leung, S.P., Spurgeon, P.C. and Cheung, H.K. Job satisfaction and stress among ward-based and community-based psychiatric nurses. Hong Kong Journal of Psychiatry. 2007; 17 (2): 45-54.

35. Dignani, L. and Toccaceli, A. Nurses and job satisfaction: results of an Italian survey. Journal of US-China Public Administration. 2013; 10 (4): 379-387.

36. Estes, B. Abusive supervision and nursing performance. Nursing Forum. 2013; 48 (1): 3-16.

37. Nayeri, N.D. and Negarandeh, R. Conflict among Iranian nurses: a qualitative Study. Human Resources for Health. 2009; 7:25.

38. Mtengezo J. Improving nurse retention: factors influencing job satisfaction of all cadres of nurses at Machinga District Hospital. College of Medicine MPH dissertations. 2008. Accessed at http://www. medcol.mw/commhealth $/ \mathrm{mph} /$ dissertations $/ \mathrm{mph}$ _dissertations.htm on $8 / 06 / 2014$

39. The Malawi Public Service Regulation. Malawi Government, Zomba. 1991.

40. Hamama, L., Tartakovsky, E., Eroshina, K., Patrakov, E., Golubkova, A., J. Bogushevich, J. and Shardina, L. Nurses' job satisfaction and attitudes towards people living with HIV/AIDS in Russia. International Nursing Review. 2013; 61 (1): 131-139.

41. Celic, S. and Hisar. F. The influence of the professionalism behavior of nurses working in health institutions on job satisfaction. International Journal of Nursing Practice. 2012; 18 (2): 180-187.

42. Gurkova, E., Cap, J., Ziakova, K. and Duriskova, M. Job satisfaction and emotional subjective well-being among Slovak nurses. International Nursing Review. 2012; 59 (1): 94-100.

43. Lu, H., Barriball, K.L., Zhang,X. A. and While, A.E. Job satisfaction among hospital nurses revisited: a systematic review. International Journal of Nursing Studies. 2012; 49 (8): 1017-1038.

44. Hayes, B., Bonner, A. and Pryor, J. Factors contributing to nurse job satisfaction in the acute hospital setting: a review of recent literature. Journal of Nursing Management. 2010; 18 (7): 804-814. 